\title{
Preconception sex selection demand and preferences in the United States
}

\author{
Edgar Dahl, Ph.D., ${ }^{\mathrm{a}}$ Ruchi S. Gupta, M.D., M.P.H., ${ }^{\mathrm{b}}$ Manfred Beutel, M.D.,, \\ Yve Stoebel-Richter, Ph.D., ${ }^{\mathrm{d}}$ Burkhard Brosig, M.D., ${ }^{\mathrm{e}}$ Hans-Rudolf Tinneberg, M.D., ${ }^{\mathrm{f}}$ \\ and Tarun Jain, M.D. ${ }^{\mathrm{g}}$ \\ ${ }^{a}$ Center for Bioethics and Humanities, State University of New York Upstate Medical University, Syracuse, New York; \\ ${ }^{\mathrm{b}}$ Institute for Healthcare Studies, Northwestern University Feinberg School of Medicine, Chicago, Illinois; ${ }^{\mathrm{c}}$ Clinic for \\ Psychosomatic Medicine and Psychotherapy, University of Mainz, Mainz, Germany; ${ }^{\mathrm{d}}$ Department of Psychology and Medical \\ Sociology, University of Leipzig, Leipzig, Germany; ${ }^{\mathrm{e}}$ Clinic for Psychosomatic Medicine and Psychotherapy, University of \\ Giessen, Germany; ${ }^{\mathrm{f}}$ Department of Obstetrics and Gynecology, University of Giessen, Germany; and ${ }^{\mathrm{g}}$ Department of \\ Obstetrics and Gynecology, University of Illinois College of Medicine, Chicago, Illinois
}

Objective: Preconception sex selection for nonmedical reasons raises important moral, legal, and social issues. The main concern is based upon the assumption that a widely available service for sex selection will lead to a socially disruptive imbalance of the sexes. For a severe sex ratio distortion to occur, however, at least two conditions have to be met. First, there must be a significant preference for children of a particular sex, and second, there must be a considerable interest in employing sex selection technology. Our objective was to ascertain such demand and preferences among the United States general population.

Design: Cross-sectional web-based survey.

Setting: United States general population.

Patient(s): One thousand one hundred ninety-seven men and women aged 18 to 45 years.

Intervention(s): None

Main Outcome Measure(s): Web-based questionnaire assessing preferences for sex of children and demand for preconception sex selection for nonmedical reasons.

Result(s): Eight percent of respondents would use preconception sex selection technology, $74 \%$ were opposed, and $18 \%$ were undecided. If the sex selection process was simplified to taking a pill, $18 \%$ would be willing to use such a medication, $59 \%$ were opposed, and $22 \%$ were undecided. In terms of gender choices, $39 \%$ of respondents would like their first child to be a son, $19 \%$ would like their first child to be a daughter, and $42 \%$ had no preference. Overall, $50 \%$ wished to have a family with an equal number of boys and girls, $7 \%$ with more boys than girls, $6 \%$ with more girls than boys, $5 \%$ with only boys, $4 \%$ with only girls, and $27 \%$ had no preference.

Conclusion(s): Preconception sex selection technology via sperm separation is unlikely to be used by the majority of the United States population and is unlikely to have a significant impact on the natural sex ratio. (Fertil Steril ${ }^{\circledR}$ 2006;85:468-73. (C2006 by American Society for Reproductive Medicine.)

Key Words: Sex selection, sperm sorting, MicroSort, gender preferences, sex ratio, social survey, law, ethics, health policy

Preconception sex selection technology that separates $\mathrm{X}$ - and Y-bearing sperm is currently available in the United States as part of an FDA-approved clinical trial via the Genetics and IVF Institute (Fairfax, VA) and over 100 collaborating clinics in 30 states (1). The technology employs a flow cytometer that separates the $2.8 \%$ heavier X-from Y-bearing sperm to produce an $\mathrm{X}$ - or $\mathrm{Y}$-enriched sperm sample for artificial insemination or in vitro fertilization $(2-4)$. Upon successful completion of the clinical trial (which began in 1995), the potential exists for widespread dissemination

Received May 25, 2005; revised and accepted July 22, 2005

Reprint requests: Tarun Jain, M.D., Division of Reproductive Endocrinology and Infertility, University of Illinois Medical Center, 820 South Wood Street, M/C 808, Chicago, Illinois 60612 (FAX: 3129964238; E-mail: tjain@uic.edu). and marketing of this technology throughout the United States (5).

Because use of such technology poses important moral, legal, and social issues, it has become one of the most controversial topics in bioethics today (6-9). Some concerns include an inappropriate use of limited medical resources (10), the perpetuation of sexist attitudes that reinforce discrimination against women (11), the fear that children born as a result of sex selection may be expected to act in certain gender-specific ways (12), and the acceleration of trends toward selection of offspring characteristics and the creation of "designer babies" (13).

The main concern, however, is that a widely available service for preconception sex selection may distort the natural sex ratio and lead to a socially disruptive imbalance of the sexes, as has occurred in countries such as 
China and India (14-20). Even uncompromising advocates of procreative liberty concede that a severe distortion of the sex ratio would justify limits on reproductive freedom (21-26).

However, whether or not a sex ratio distortion poses a real threat to Western societies is an empirical question that cannot be answered by intuition, but only by evidence. For a severe sex ratio distortion to occur, at least two conditions must be met. First, there must be a marked preference for children of a particular sex, and, second, there must be a considerable demand for a reproductive service for preconception sex selection. Moreover, both conditions need to be met simultaneously. For example, if there was a marked preference for children of a particular sex but couples were unwilling to use sex selection technology (because it was thought to be too intrusive, too expensive, or immoral), then a widely available service for sex selection would not have a significant demographic impact.

To determine whether or not these two conditions are met, we conducted a nationwide representative survey on gender preferences and demand for preconception sex selection in the United States.

\section{MATERIALS AND METHODS}

A self-administered, web-based survey was conducted using a previously validated questionnaire (Table 1) (27). Harris Interactive (Rochester, NY), a market-research firm specializing in internet-based research methods, was commissioned to conduct the nationwide survey, drawing upon its Harris Poll Online Panel to identify potential

\section{TABLE 1}

\section{Questionnaire.}

Suppose you did not have any children but would very much want to.

1. If given a choice, would you like your first born child to be
a boy
a girl
do not care
not sure

2. If you would like to have more than one child, would you prefer to have

only boys

only girls

more boys than girls

more girls than boys

an equal number of boys and girls

do not care

not sure

3. It may soon be possible for parents to choose the sex of their children. Couples interested in such a service would have to visit a Fertility Center, provide a sperm sample, undergo an average of three to five cycles of intrauterine insemination, and pay a fee of approximately $\$ 2,500$ per attempt. Would you take advantage of this technology?

yes

not sure

4. Suppose, the procedure would require just a single cycle of intrauterine insemination, could be performed in any doctor's office, and would be covered by your health insurance. Would you then consider taking advantage of it?

yes

no

not sure

5. Suppose, there was a medication enabling parents to choose the sex of their children. Couples simply had to ingest a blue pill to ensure the birth of a boy or a pink pill to ensure the birth of a girl. Would you take advantage of such a medication?

yes

no

not sure

Dahl. Sex selection. Fertil Steril 2006. 
respondents (who were invited to participate in the survey via e-mail).

The five-question survey was conducted between September 1 and 3, 2004, of a sample of 1,197 men and women between the ages of 18 and 45 throughout the United States. Each respondent was issued a unique password to guard against multiple responses from any participants. A proprietary web-based technology that enables large numbers of respondents to simultaneously complete the survey was used.

The demographic characteristics (age, sex, ethnicity, education, income, marital status, and region of residence) of the population sampled were weighted where necessary to reflect United States census estimates of American adults aged 18 to 45 . Propensity score weighting was also used to adjust for respondents' propensity to use the internet. In theory, with a probability sample of this size, one could say with $95 \%$ certainty that the results have a sampling error of \pm 3 percentage points owing to the probability that a sample is not a perfect cross-section of the total population from which it was drawn). All Harris Interactive surveys are designed to comply with the code and standards of the Council of American Survey Organizations (CASRO) and the code of the National Council of Public Polls.

\section{RESULTS}

The demographic characteristics of the survey respondents are presented in Table 2 . Both men and women responded equally to the survey (49\% and $51 \%$, respectively). Married respondents made up 53\%, with most having some college or more $(61 \%)$, and most working full or part time (58\%). Some demographic questions were not answered by every respondent.

The computer-tabulated results for each survey question are as follows:

1. Participants were asked if, given a choice, they would want their first child to be male or female. Thirty-nine percent of respondents would like their first child to be a boy, $19 \%$ would like the first child to be a girl, and $42 \%$ stated that they have no preference about the sex of their first child (Fig. 1A). The divorced/separated group was less likely to have a sex preference (28\% for a boy and $17 \%$ for a girl) than the married participants (38\% for a boy and $21 \%$ for a girl) and the single/ never-married participants ( $43 \%$ for a boy and $13 \%$ for a girl).

2. Provided they would like to have more than just one child, participants were asked, if, given a choice, they would want only boys, only girls, more boys than girls, more girls than boys, as many girls as boys, or whether the sex of their children would not matter to them at all. Five percent preferred only boys, $4 \%$ only girls, $7 \%$ more boys than girls, $6 \%$ more girls than boys, $50 \%$ as many girls as boys, and $27 \%$ had no preference (Fig. 1B).

\section{TABLE 2}

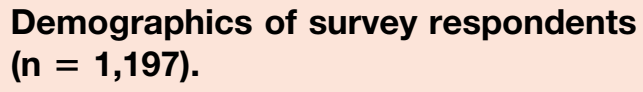

\begin{tabular}{lc}
$\begin{array}{l}\text { Gender } \\
\text { Male }\end{array}$ & $587(49.0 \%)$ \\
Female & $610(51.0 \%)$ \\
Age (ys) & \\
18-34 & $692(57.8 \%)$ \\
35-45 & $505(42.2 \%)$ \\
Marital status & \\
$\quad$ Single/never married & $406(37.4 \%)$ \\
Married & $576(53.0 \%)$ \\
Divorced/separated & $104(9.6 \%)$ \\
Region of residence & \\
Northeast & $214(18.0 \%)$ \\
Midwest & $243(20.4 \%)$ \\
South & $425(35.7 \%)$ \\
West & $310(26.0 \%)$ \\
Education (highest level) & \\
High school or less & $473(39.5 \%)$ \\
Some college & $396(33.1 \%)$ \\
4-year college or more & $328(27.4 \%)$ \\
Household income & \\
$\quad$ \$35,000 & $375(35.2 \%)$ \\
\$35,000-\$49,999 & $158(14.8 \%)$ \\
\$50,000-\$74,999 & $203(19.1 \%)$ \\
> \$75,000 & $329(30.9 \%)$ \\
Employment status & \\
Full-time/self-employed & $674(47.8 \%)$ \\
Part-time & $144(10.2 \%)$ \\
Student & $186(13.2 \%)$ \\
Unemployed & $392(27.8 \%)$ \\
Retired & $15(1.0 \%)$ \\
\hline
\end{tabular}

Dahl. Sex selection. Fertil Steril 2006.

3. Participants were then asked if they could imagine selecting the sex of their children via sperm separation technology. In order to make an informed decision, participants were given details on the procedure and its cost. Whereas $8 \%$ of respondents could imagine taking advantage of such technology, $74 \%$ were opposed, and $18 \%$ were undecided (Fig. 1C).

4. To establish whether the $92 \%(n=1,103)$ who were either opposed or undecided toward using sperm separation technology for sex selection were in fact not interested in sex selection or simply found the procedure to be too demanding, we asked them if they could imagine using this technology if it could be performed in any doctor's office, required only a single cycle of intrauterine insemination, and was covered by their health insurance. Given these less demanding circumstances, $12 \%$ would use such technology, $64 \%$ were opposed, and $24 \%$ were undecided (Fig. 1D). 
(A) Gender preferences for first child ( $n=1,197)$. (B) Gender preferences for all children born $(n=1,197)$. (C) Interest in preconception sex selection when couples have to undergo three to five cycles of intrauterine insemination and have to pay for the treatment themselves $(n=1,197)$. (D) Among the $92 \%$ of couples not interested in sex selection with the conditions noted in Figure 1C, the interest in preconception sex selection if couples had to undergo just a single cycle of intrauterine insemination and treatment were covered by health insurance $(n=1,103)$. $(E)$ Interest in preconception sex selection if there were a medication to select the sex of their children $(n=1,197)$.

A

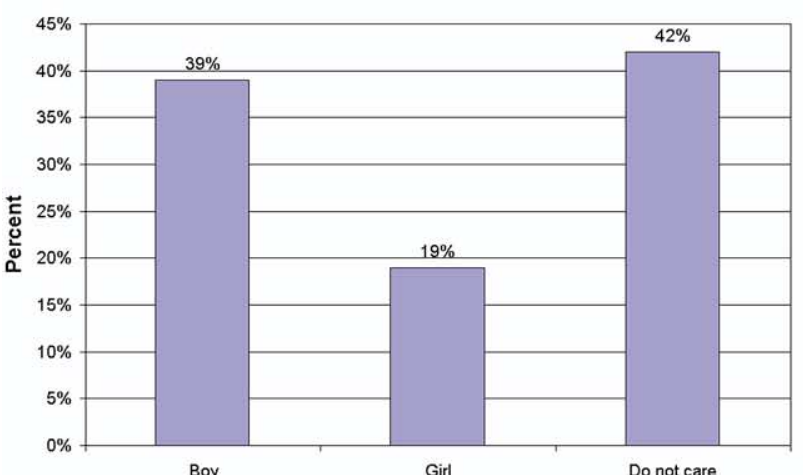

C Interest in using sex selection in the US

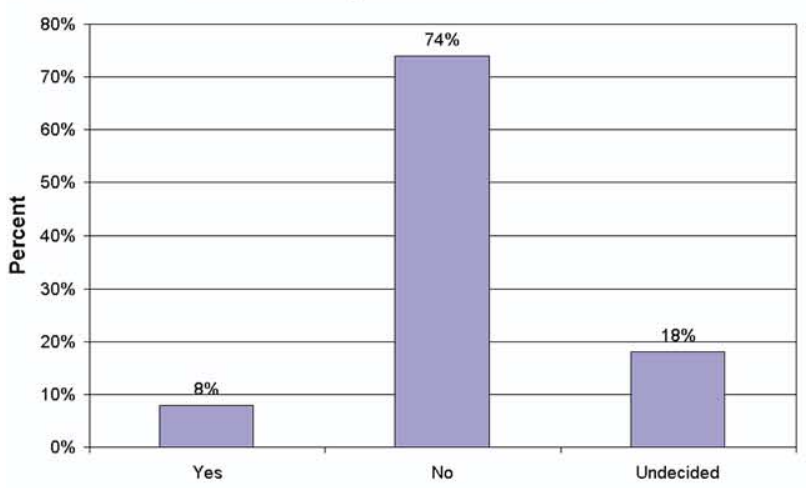

E

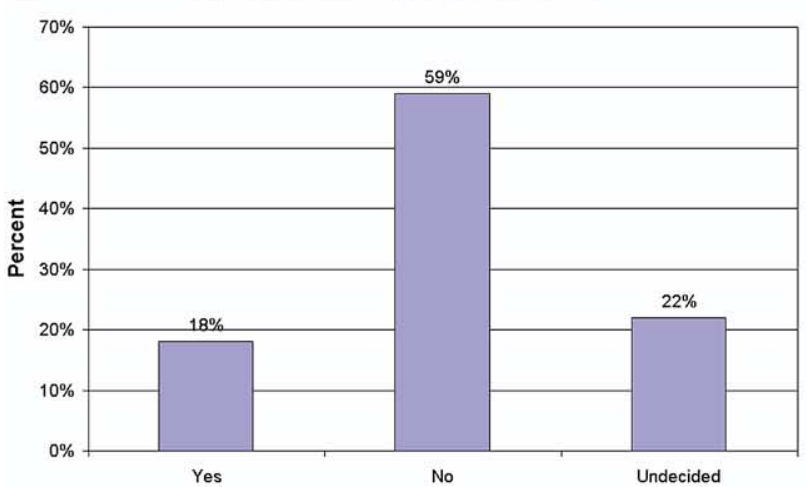

Yes

Dahl. Sex selection. Fertil Steril 2006
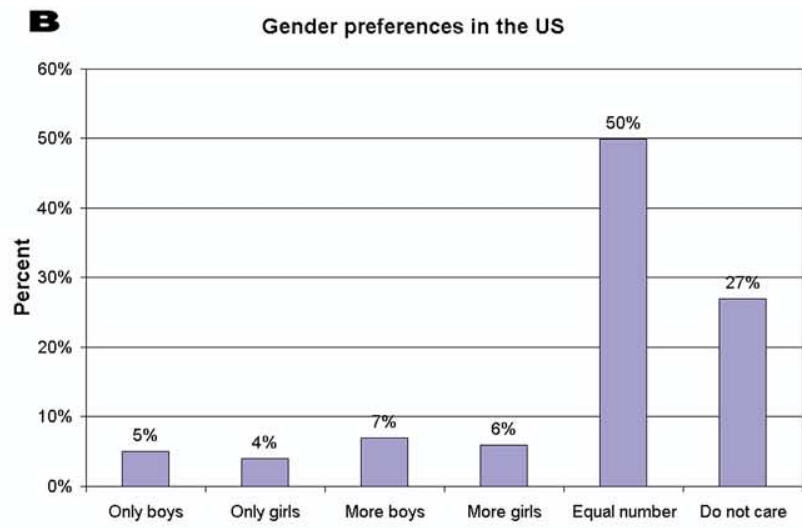

D Interest in using sex selection in the US

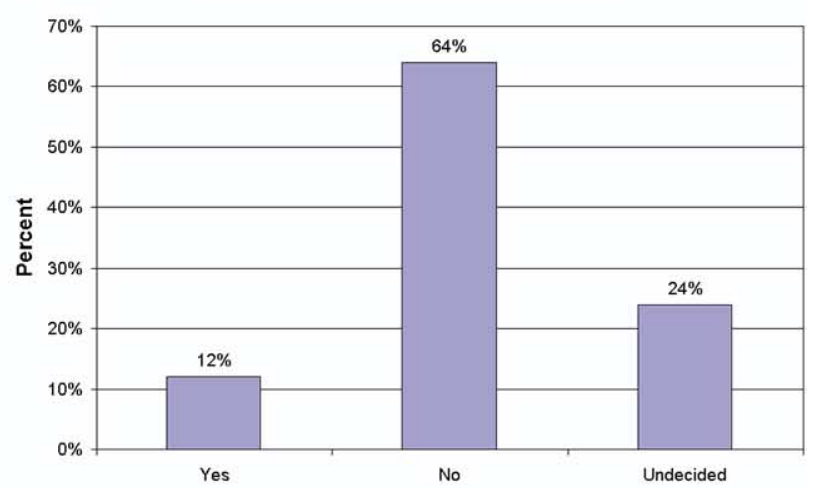

5. Finally, we asked the participants to imagine there was a medication to select the sex of their children. Rather than visiting a fertility center, they would simply have to take a "pink pill" to ensure the birth of a girl or a "blue pill" to ensure the birth of a boy. While $18 \%$ would be willing to use such a medication, 59\% were opposed, and $22 \%$ were undecided (Fig. 1E). Compared to the $8 \%$ of respondents in question 3 who were willing to use sex selection, the $18 \%$ of respondents who were willing to use "a pill" were more likely to have a household income less than 
$\$ 35,000$ ( $22 \%$ versus $6 \%$ ) and to have a high school education or less (19\% versus $6 \%)$.

Individual answers to all five questions posed did not yield any significant differences by age, sex, ethnicity, education, or income.

\section{DISCUSSION}

To our knowledge, this is the first study in the medical literature that examines the demand and preferences for preconception sex selection technology among a representative general population of the United States. Our study shows that only $8 \%$ of Americans would consider using preconception sex selection technology for nonmedical reasons. If the process were simplified to taking a pill, only $18 \%$ would wish to choose the sex of their child. Furthermore, the majority of Americans (77\%) either prefer to have an equal number of boys and girls or have no preference.

The results of our study are consistent with findings from prior social research. For example, based on a cross-cultural survey on parental gender preferences conducted in the 1970s, Nancy E. Williamson predicted that "if a reasonably practical, safe, and effective method of sex selection were to become available, it will probably be used by relatively few couples and mostly to have at least one child of each sex" $(28,29)$.

In an extensive social survey of 5,981 married women under 45 years of age residing in the United States, Westoff and Rindfuss (30) found striking evidence for the desire to have a balanced sex composition of their family: "Despite a strong preference for a first-born boy, the gender preferences for subsequent children were overwhelmingly determined by the sex of existing children: $85 \%$ of women with two boys indicated a preference for a girl, and $84 \%$ of women with two girls registered a preference for a boy. [...] Overall, $51.1 \%$ preferred the next child to be male, and $48.9 \%$ preferred the next child to be female, yielding a sex ratio of 104 . In terms of sampling error, this is indistinguishable from the current sex ratio of 105 . Thus, the implication is that, apart from the transitional period, sex control technology would have very little effect on the sex ratio at birth."

According to a survey among 140 primiparous American women conducted by Steinbacher and Gilroy (31), 18\% preferred to have a boy, $23 \%$ preferred to have a girl, and $59 \%$ expressed no preference at all. Asked, "If the means were available to you so that you could have selected the sex of your child, would you have done so?," $18 \%$ answered yes, $53 \%$ no, and $29 \%$ were undecided. Of the 26 women who said they would have used sex selection, 13 would have done so to ensure the birth of a boy and 13 would have done so to ensure the birth of a girl.

In a recent survey conducted by Jain et al. (32), among 561 American infertility patients, $229(40.8 \%)$ women stated that they would like to be able to choose the sex of their children as part of their infertility treatment. Of these 229 women, $13(5.7 \%)$ had children of both sexes, 111 (48.4\%) had children of only one sex, and 105 (45.9\%) had no children at all. Of the 13 women having children of both sexes, $5(38.5 \%)$ preferred to have another boy, and 8 $(61.5 \%)$ preferred to have another girl. Of the 105 women having no children, 36 (34.3\%) desired to have a boy, and 69 $(65.7 \%)$ desired to have a girl. Additionally, of the 111 women having children of only one sex, $37(74.0 \%)$ mothers of girls wished for a boy, and $50(82.0 \%)$ mothers of boys wished for a girl. In other words, "Among parous women, those with only daughters significantly desired to select a male child, whereas those with sons significantly desired to select a female child" (32).

It is certainly interesting that in the study by Jain et al. (32), a larger proportion of infertility patients expressed a desire for sex selection (40.8\%) compared to our findings in the general population (8\%). There could be several potential reasons for this discrepancy. Infertility patients are more familiar with procedures such as intrauterine insemination, and thus may not see sex selection as a cumbersome process. Also, infertility patients may wish to choose the sex of their next child since they may perceive that their likelihood of having future children is limited. Data on these potential factors, however, are lacking.

There can sometimes be quite a difference between what people say and what they actually do. Thus, it is quite reassuring that other demographic research that has focused on examining when couples stop having more children does indeed confirm the stated preference for a gender-balanced family. In the United States, couples with two boys and couples with two girls are significantly more likely to have a third child than couples with one boy and one girl, suggesting that parents with children of both sexes are more content with their family composition (33-36).

Perhaps even more instructive than social surveys and demographic research are data collected by fertility clinics already offering preconception sex selection. According to a report of a fertility center in New York City, all of the 120 American couples seeking sex selection were doing so for the sole purpose of family balancing: "They selected girls when they had boys at home and boys when there were only girls" (37). Likewise, Gametrics Limited in Alzada, Montana, which detailed the collective experience of 65 fertility clinics, states, "The overwhelming majority had two or more children of the same sex and desired a child of the opposite sex" (38). Finally, the Genetics \& IVF Institute in Fairfax, Virginia, reports, "The majority of couples $(>90.5 \%)$ in our study were seeking gender pre-selection for family balancing purposes, were in their mid-thirties, had two or three children of the same sex, and desired only one more child" (39).

It is only a matter of time before preconception sex selection technology becomes widely available and marketed throughout the United States. With the numerous ethical issues posed by use of such technology, our study provides 
some reassurance that preconception sex selection is unlikely to be used by the majority of the population and is unlikely to have a significant impact on the natural sex ratio.

\section{REFERENCES}

1. Genetics and IVF Institute. Microsoft sperm separation. Available at: http://www.microsort.net/index.htm. Accessed May 16, 2005.

2. Johnson LA, Welch GR, Keyvanfar K, Dorfmann A, Fugger EF, Schulman JD. Gender preselection in humans? Flow cytometric separation of $\mathrm{X}$ and $\mathrm{Y}$ spermatozoa for the prevention of $\mathrm{X}$-linked diseases. Hum Reprod 1993;8:1733-9.

3. Vidal F, Fugger EF, Blanco J, Keyvanfar K, Catala V, Norton M, et al. Efficiency of MicroSort flow cytometry for producing sperm populations enriched in $\mathrm{X}$ - or Y-chromosome haplotypes: a blind trial assessed by double and triple colour fluorescent in-situ hybridization. Hum Reprod 1998;13:308-12.

4. Fugger EF, Black SH, Keyvanfar K, Schulman JD. Births of normal daughters after MicroSort sperm separation and intrauterine insemination, in-vitro fertilization, or intracyto-plasmic sperm injection. Hum Reprod 1998;13:2367-70

5. Schulman JD, Karabinus D. Scientific aspects of preconception gender selection. Reprod BioMed Online 2005; 10(Suppl 1):111-5.

6. Ethics Committee of the American Society for Reproductive Medicine. Preconception gender selection for nonmedical reasons. Fertil Steril 2001;75:861-4.

7. Human Fertilisation and Embryology Authority. Sex selection: options for regulation. London: HFEA; 2003.

8. President's Council on Bioethics. Beyond therapy: biotechnology and the pursuit of happiness. President's Council on Bioethics: Washington (DC); 2003.

9. The Science and Technology Committee. Human reproductive technologies and the law. London: House of Commons; 2005.

10. Hill DL, Surrey MW, Danzer HC. Is gender selection an appropriate use of medical resources? J Assist Reprod Genet 2002;19:438-9.

11. Dai J. Preconception sex selection: the perspective of a person of the undesired gender. Am J Bioethics 2001;1:37-8.

12. Davis D. Genetic dilemmas: reproductive technology, parental choices, and children's futures. New York: Routledge; 2001.

13. Fukuyama F. Our posthuman future: consequences of the biotechnology revolution. New York: Farrar Straus \& Giroux; 2002.

14. Benagiano G, Bianchi P. Sex preselection: an aid to couples or a threat to humanity? Hum Reprod 1999;14:870-2.

15. Allahbadia GN. The 50 million missing women. J Assist Reprod Genet 2002;19:411-6.

16. Plafker T. Sex selection in China sees 117 boys born for every 100 girls. BMJ 2002;324:1233.

17. Hudson VM, Den Boer AM. Bare branches: the security implications of Asia's surplus male population. Cambridge: MIT Press; 2004.

18. Sen A. Missing women-revisited. BMJ 2003;327:1297-8.
19. Chan CLW, Yip PSF, Ng EHY, Ho PC, Chan CHY, Au JSK. Gender selection in China: its meanings and implications. J Assist Reprod Genet 2002;19:426-30.

20. United Nations Population Fund. Missing: mapping the adverse child sex ratio in India. Delhi: UNPF; 2003.

21. Singer P, Wells D. The reproduction revolution: new ways of making babies. Oxford: Oxford University Press; 1984.

22. Warren MA. Gendercide: the implications of sex selection. San Francisco: Rowman \& Allanheld; 1985.

23. Glover J. Comments on some ethical issues in sex selection. In: Sureau C, Shenfield F, editors. Ethical aspects of human reproduction. Paris: John Libbey; 1995. p. 305-13.

24. Robertson JA. Preconception gender selection. Am J Bioethics 2001; 1:2-9.

25. Dickens BM. Can sex selection be ethically tolerated? J Med Ethics 2002;28:335-6.

26. Dahl E. Sex selection: laissez faire or family balancing? Health Care Anal 2005;13:87-90.

27. Dahl E, Beutel M, Brosig B, Hinsch KD. Preconception sex selection for nonmedical reasons: a representative survey from Germany. Hum Reprod 2003;18:2231-4.

28. Williamson NE. Sons or daughters: a cross-cultural survey of parental preferences. Beverly Hills: Sage; 1976.

29. Williamson NE. Parental sex preferences and sex selection. In: Bennett NG, editor. New York: Academic Press; 1983. p. 129-45.

30. Westoff CF, Rindfuss RR. Sex preselection in the United States: some implications. Science 1974;184:633-6.

31. Steinbacher R, Gilroy FD. Preference for sex of child among primiparous women. J Psychol 1985;119:541-7.

32. Jain T, Missmer SA, Gupta RS, Hornstein MD. Preimplantation sex selection demand and preferences in an infertility population. Fertil Steril 2005;83:649-58.

33. Westoff CF, Potter RG, Sagi P. The third child: a study in the prediction of fertility. Princeton: Princeton University Press; 1963.

34. Sloane DM, Lee CF. Sex of previous children and intentions for further births in the United States, 1965-1976. Demography 1983;20:353-67.

35. Yamaguchi K, Ferguson LR. The stopping and spacing of childbirths and their birth-history predictors: rational choice theory and eventhistory analysis. Am Sociol Rev 1995;60:272-98.

36. Pollard MS, Morgan SP. Emerging parental gender indifference? Sex composition of children and the third birth. Am Sociol Rev 2002;67: $600-13$.

37. Khatamee MA, Leinberger-Sica A, Matos P, Weseley AC. Sex preselection in New York City: who chooses which sex and why. Int J Fertil 1989;34:353-4.

38. Beernink FJ, Dmowski WP, Ericsson RJ. Sex preselection through albumin separation of sperm. Fertil Steril 1993;59:382-6.

39. Fugger EF, Black SH., Keyvanfar K, Schulman, JD. Births of normal daughters after MicroSort sperm separation and intrauterine insemination, in-vitro-fertilization, or intracy-toplasmic sperm injection. Hum Reprod 1998;13:2367-70. 